УДК 621.771 .252

Максименко О. П. Оробцев А. Ю. Самохвал В. М. Штода М. М. Марченко К. К.

\title{
МЕТОДИКА ИССЛЕДОВАНИЯ И АНАЛИЗ ИЗНОСА КАЛИБРОВ ВАЛКОВ ПРОВОЛОЧНОГО БЛОКА
}

Исследование износа и стойкости деталей машин получило широкое отображение в известных трудах отечественных [1-3] и зарубежных [4, 5] ученых. Значительные работы в этой области выполнены и специалистами по обработке металлов давлением [6-8]. Известно, что износ в очаге деформации при прокатке зависит от физических, химических и механических условий в нем, а также от температуры металла на контакте. При оценке износа следует учитывать зависимость интенсивности изнашивания от физико-химического воздействия окружающей среды (вода, окалина, смазка), наличия значительных градиентов полей напряжений и деформаций, от кинематики процесса, включая скольжение в зоне контакта полосы с валками. Необходимо также иметь в виду и возможность появления дефектов в поверхностных слоях, а также неоднородность и анизотропность их свойств. Механизм изнашивания рабочего инструмента при прокатке включает такие составляющие как задир поверхности, заедание, выкрашивание и истирание. Наиболее тяжелой формой повреждения поверхности рабочего инструмента при горячей прокатке является абразивный износ, включающий в себя все выше перечисленные составляющие, действие которых усугубляется высокой температурой деформации металла и подачей охлаждающей воды.

Несмотря на то, что валки проволочного блока изготавливают из твердосплавного материала, за время кампании работы ручьи калибров подвергаются значительной выработке. В связи с этим, целью настоящей работы является разработка методики экспериментального изучения износа валков проволочного блока среднесортно-проволочного стана 400/200 ПАО «ДМК». Обычно выработку калибров измеряют с помощью часового индикатора, точность которого составляет $\pm 0,01$ мм. Известны также и другие способы измерения износа калибров [9].

Особенностью калибров проволочного блока является их относительно небольшие размеры. Поэтому с помощью часового индикатора удается измерить величину износа только в средней части калибра. Опыты показывают, что в ряде случаев, максимальный износ возникает в стороне от центральной части калибров. В этих условиях возникает задача определения выработки калибров по всей длине его поперечного сечения. Решение этой задачи было достигнуто путем разработки оптико-светового метода изучения выработки калибров валков и создания специального измерительного устройства.

Целью работы является обоснование применения методики измерения износа валков с использованием оптико-светового стенда и анализ особенностей износа калибров валков проволочного блока.

В качестве измерительного устройства использовали оптико-световой стенд, показанный на рис. 1. Установка включает источник света, увеличительные линзы, экран и фотоаппарат для фиксации изображения. При изучении износа ручьев калибра валок располагают между источником света и линзой на расстоянии фокуса от последней. В ручей калибра устанавливают шаблон и с помощью специального приспособления строго фиксируют его положение. При включении света на экране стенда возникает увеличенное изображение зазора между дном ручья и шаблоном (рис. 1). Процесс измерения износа калибра включает две стадии. На первом этапе на экране получают обратное (перевернутое) изображение просвета между ручьем нового (до установки в клеть) валка и шаблона. Заметим, что этот 
просвет, в результате действия линзы, в шесть раз превышает реальный. Затем полученное на экране изображение фотографировали совместно с эталоном длины (специальная измерительная линейка для масштабирования) и с помощью компьютера определяли размеры реального просвета между ручьем калибра нового валка и шаблоном. На втором этапе выполняли те же действия, но для отработавшего кампанию валка. Разница размеров конечного и начального просвета между ручьем и шаблоном представляет картину износа калибра в поперечном сечении валка. На рис. 2 и 3 приведены фотографии зазоров между выработанными калибрами валков и шаблонами десяти клетей проволочного блока, а также микрорельеф поверхности вываленных валков. Цифрами на фото отмечены величины зазоров на указанных участках поперечного сечения калибра. Заметим, что в первых семи клетях проволочного блока валки имеют по два одинаковых калибра. В остальных трех клетях каждый из валков имеет по четыре калибра. При проведении опытов в первой группе клетей использовали только один калибр, на валках которых было прокатано 2756 т металла, в 8-10 клетях прокатку осуществляли в двух калибрах с тоннажем в 1350 т и 1406 т.

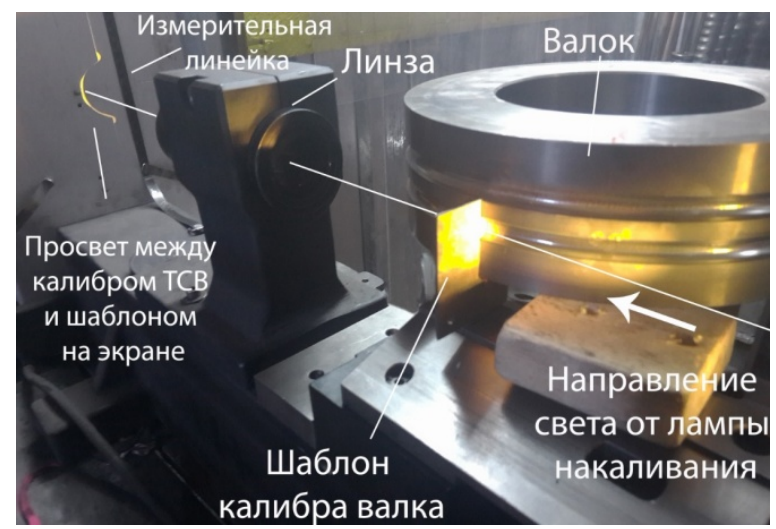

Рис. 1. Стенд с валком, шаблоном и изображением зазора

В табл. 1 приведены условия деформации и размеры калибров валков, а также среднее давление и усилие прокатки по клетям проволочного блока.

Таблица 1

Размеры калибров, режим деформации и сила прокатки при производстве катанки диаметром 5,5 мм в проволочном блоке

\begin{tabular}{|c|c|c|c|c|c|c|c|}
\hline \multirow{2}{*}{$\begin{array}{c}\text { № } \\
\text { модуля }\end{array}$} & \multicolumn{2}{|c|}{ Размеры калибров, мм } & \multirow{2}{*}{$\begin{array}{c}\text { Зазор (мм) по } \\
\text { буртам } \\
\mathrm{g}\end{array}$} & \multicolumn{2}{|c|}{$\begin{array}{c}\text { Размеры } \\
\text { раскатов, мм }\end{array}$} & \multirow{2}{*}{$\begin{array}{c}\text { Среднее } \\
\text { давление, } \\
\text { МПа }\end{array}$} & \multirow{2}{*}{$\begin{array}{c}\text { Сила } \\
\text { прокатки, } \\
\text { кН }\end{array}$} \\
\hline & $\mathrm{Bk}$ & hвр & & hi & bi & & \\
\hline & & & & 17,2 & 17,2 & & \\
\hline 1 & 23,65 & 4,6 & 1,94 & 11,14 & 20,65 & 284,96 & 92,59 \\
\hline 2 & 13,83 & 6,14 & 1,51 & 13,74 & 13,79 & 291,08 & 72,16 \\
\hline 3 & 18,89 & 3,5 & 1,85 & 8,85 & 16,97 & 309,57 & 77,56 \\
\hline 4 & 11,45 & 4,95 & 1,13 & 11,03 & 11,03 & 309,47 & 56,51 \\
\hline 5 & 16,85 & 2,7 & 1,22 & 6,62 & 13,9 & 317,99 & 60,47 \\
\hline 6 & 8,97 & 3,7 & 1,36 & 8,66 & 8,76 & 307,71 & 42,40 \\
\hline 7 & 13,56 & 2,1 & 1,06 & 5,26 & 10,97 & 304,99 & 40,64 \\
\hline 8 & 7,27 & 2,92 & 1,11 & 6,95 & 6,95 & 299,21 & 29,32 \\
\hline 9 & 10,24 & 1,6 & 0,99 & 4,19 & 8,75 & 300,58 & 28,57 \\
\hline 10 & 5,76 & 2,18 & 1,21 & 5,57 & 5,57 & 286,29 & 19,63 \\
\hline
\end{tabular}

Прежде чем анализировать результаты исследования, приведенные на рис. 2 и 3, оценим точность измерения выработки валков с помощью оптико-светового стенда в сравнении с показаниями часового индикатора. В обоих случаях замеры выполняли по центру калибра после кампании работы валков.

Результаты измерения износа во всех клетях проволочного блока приведены в табл. 2-3. 
Таблица 2

Результаты измерения износа калибров валков оптико-световым методом

\begin{tabular}{|c|c|c|c|c|c|c|c|c|c|c|c|}
\hline \multirow{2}{*}{$\begin{array}{c}\text { Ручьи } \\
\text { калибра }\end{array}$} & \multirow{2}{*}{$\begin{array}{c}\text { № } \\
\text { калибра }\end{array}$} & \multicolumn{10}{|c|}{ Номер клети проволочного блока } \\
\hline & & 1 & 2 & 3 & 4 & 5 & 6 & 7 & 8 & 9 & 10 \\
\hline \multirow{4}{*}{ верхний } & 1 & 0,32 & 0,23 & 0,59 & 0,1 & 0,24 & 0,05 & 0,24 & 0,09 & 0,11 & 0,11 \\
\hline & 2 & 0,32 & 0,28 & 0,39 & 0,07 & 0,27 & 0,14 & 0,28 & 0,10 & 0,13 & 0,13 \\
\hline & 3 & & & & & & & & 0,12 & 0,12 & 0,10 \\
\hline & 4 & & & & & & & & 0,05 & 0,11 & 0,11 \\
\hline \multirow{4}{*}{ нижний } & 1 & 0,36 & 0,30 & 0,44 & 0,14 & 0,22 & 0,13 & 0,31 & 0,12 & 0,12 & 0,10 \\
\hline & 2 & 0,32 & 0,29 & 0,40 & 0,07 & 0,32 & 0,13 & 0,34 & 0,12 & 0,13 & 0,10 \\
\hline & 3 & & & & & & & & 0,11 & 0,11 & 0,10 \\
\hline & 4 & & & & & & & & 0,08 & 0,13 & 0,10 \\
\hline
\end{tabular}

Таблица 3

Результаты измерения износа калибров валков часовым индикатором

\begin{tabular}{|c|c|c|c|c|c|c|c|c|c|c|c|}
\hline \multirow{2}{*}{$\begin{array}{c}\text { Ручьи ка- } \\
\text { либра }\end{array}$} & \multirow{2}{*}{$\begin{array}{c}\text { № } \\
\text { калибра }\end{array}$} & \multicolumn{10}{|c|}{ Номер клети проволочного блока } \\
\hline & & 1 & 2 & 3 & 4 & 5 & 6 & 7 & 8 & 9 & 10 \\
\hline \multirow{4}{*}{ верхний } & 1 & 0,34 & 0,33 & 0,36 & 0,11 & 0,28 & 0,07 & 0,21 & 0,06 & 0,09 & 0,05 \\
\hline & 2 & 0,32 & 0,28 & 0,54 & 0,22 & 0,18 & 0,08 & 0,29 & 0,07 & 0,12 & 0,06 \\
\hline & 3 & & & & & & & & 0,09 & 0,10 & 0,02 \\
\hline & 4 & & & & & & & & 0,06 & 0,10 & 0,03 \\
\hline \multirow{4}{*}{ нижний } & 1 & 0,32 & 0,34 & 0,35 & 0,11 & 0,33 & 0,14 & 0,31 & 0,06 & 0,08 & 0,01 \\
\hline & 2 & 0,38 & 0,33 & 0,44 & 0,19 & 0,28 & 0,10 & 0,44 & 0,10 & 0,11 & 0,0 \\
\hline & 3 & & & & & & & & 0,08 & 0,05 & 0,01 \\
\hline & 4 & & & & & & & & 0,03 & 0,09 & 0,02 \\
\hline
\end{tabular}

Проведем статистический анализ полученных данных. Для этого с помощью критерия Стьюдента [10] проверим принадлежность приведенных в табл. 2 и 3 выборок одной совокупности, т. е. установим существенно ли среднее значение результатов измерений, полученные с помощью оптико-светового стенда $\overline{X_{c}}$ и часового индикатора $\overline{X_{u}}$, различаются между собой или же это различие незначимо.

Для случая, когда проверяется соответствие между средними значениями выборок, критерий Стьюдента определяется:

$$
t=\frac{\bar{X}_{c}-\bar{X}_{u}}{S_{c y M} \sqrt{\frac{1}{n_{c}}+\frac{1}{n_{u}}}}
$$

Среднеквадратическое отклонение $S_{\text {сум }}$ для обеих выборок рассчитывается по формуле:

$$
S_{c y M}=\left(\frac{\Sigma x_{i c}^{2}+\Sigma x_{i u}^{2}}{n_{c}+n_{u}-2}\right)^{0,5}
$$

где $n_{c}$ и $n_{u}$ - объемы выборок измеряемых стендом и индикатором;

$\Sigma x_{i c}^{2}$ и $\Sigma x_{i u}^{2}$-суммы квадратов разностей, относительно среднего значения выборки.

Объемы выборок, согласно данным табл. 2-3, составляют $n_{c}=n_{u}=52$.

Среднеарифметические значения выборок:

$$
\overline{X_{c}}=\frac{\Sigma X_{i c}}{n_{c}}=0,188 ; \quad \overline{X_{u}}=\frac{\Sigma X_{i u}}{n_{u}}=0,175
$$


Сумма квадратов разностей:

$$
\Sigma x_{i c}^{2}=\Sigma\left(X_{i c}-\bar{X}_{c}\right)^{2}=0,662 ; \quad \Sigma x_{i u}^{2}=\Sigma\left(X_{i u}-\bar{X}_{u}\right)^{2}=0,944
$$

Тогда

$$
t=\frac{0,188-0,175}{\left(\frac{0,662+0,944}{102}\right)^{0,5} \sqrt{\frac{1}{52}+\frac{1}{52}}}=0,523 .
$$

Табличное (критическое) значение критерия Стьюдента с надежностью $\mathrm{P}=0,99$ и степенью свободы $k=n_{c}+n_{u}-2=102$ составляет $t_{\kappa p}=2,62$. Сравнивая расчетное и критическое значения $t$, приходим к выводу, что с большой степенью надежности результаты измерений, выполненные с помощью оптико-светового стенда, существенно не отличаются от показаний часового индикатора, т. е. точность измерения износа калибров обеими приборами является достаточно близкой. Аналогичные результаты были получены при сравнении дисперсий обеих выборок с помощью критерия Фишера $[10,11]$. Следует также заметить, что показания оптико-светового стенда были проверены на нормальность распределения и установлено их соответствие кривой Гаусса.

Выполненный статистический анализ показывает, что оптико-световой метод можно уверенно применять для измерения износа калибров валков и получать данные не только по центру ручья, но и по всему периметру сечения.

Проанализируем результаты измерения износа валков, представленные на рис. 2 и 3 и в табл. 4. Как видно, в первых трех клетях наблюдается практически равномерный износ калибров от 0,2 до 0,3 мм. На поверхности ручьев проявляется абразивный и осповидный износ, особенно в первых двух клетях, а также имеет место начальная сетка термического износа. На валках второй клети наблюдается резкий переход от гладкой поверхности к шероховатой с очертаниями чередующихся выступов и впадин, что возможно связано с неполным заполнением калибра.

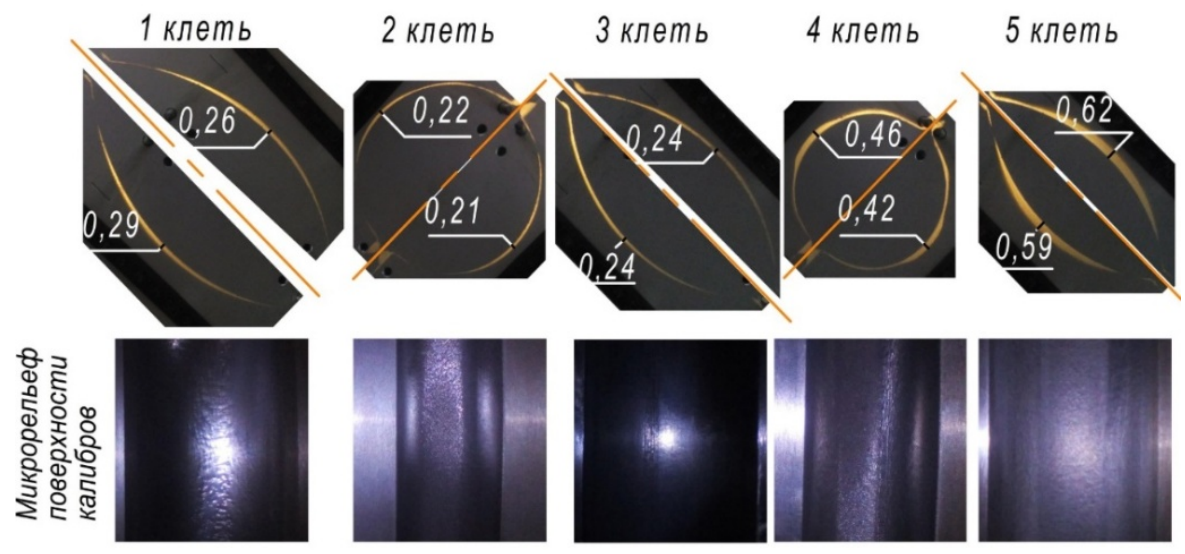

Рис. 2. Фотографии зазоров между ручьями верхнего и нижнего валков и шаблонами первых 5-ти клетей проволочного блока после кампании работы

Валки четвертой клети имеют интенсивный износ по дну калибра. Наиболее существенный износ поверхности валков наблюдается в пятой клети, достигая значений 0,5-0,6 мм, хотя поверхность остается гладкой, осповидность ее практически отсутствует. Существенная выработка поверхности валков пятой клети, по-видимому, связана со значительным средним давлением металла на валки в этом проходе и скольжением металла в очаге деформации.

В шестой клети минимальный износ расположен вблизи вертикальной линии калибра по обе стороны от нее, что предположительно связано со сваливанием раската в калибре. Минимальный износ валков этой клети наблюдается вблизи разъема калибра и составляет $0,25-0,27$ мм. 


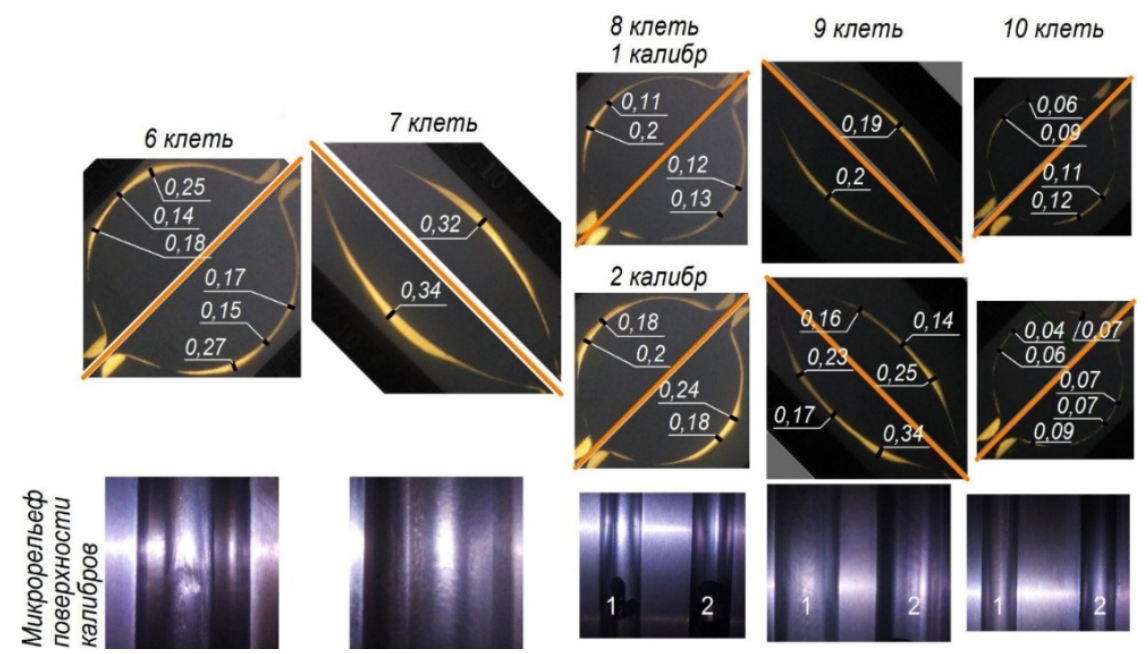

Рис. 3. Фотографии зазоров между ручьями валков и шаблонами последних пяти клетей проволочного блока

Таблица 4

Результаты исследования износа калибров валков проволочного блока стана 400/200

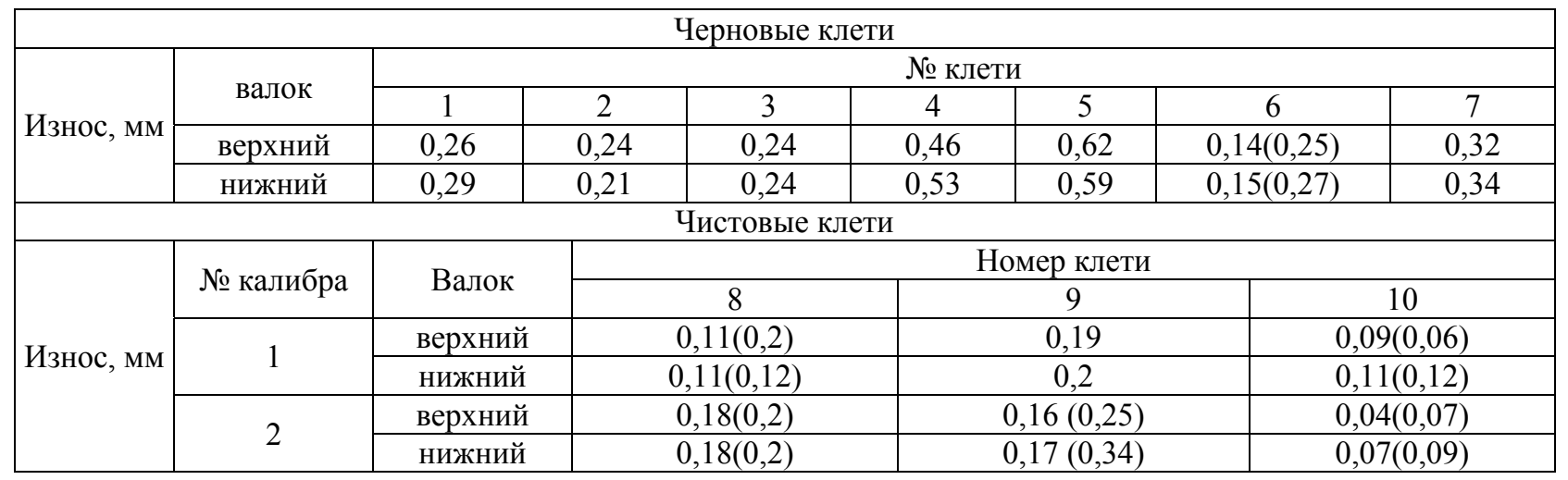

Анализируя износ рабочего инструмента 8-10 клетей, предварительно отметим, что валки имеют по четыре одинаковых калибра. На рис. 3 эти калибры показаны под номерами 1 и 2. Вначале работали калибры № 1 и на них прокатано 1350 т. Затем деформацию металла осуществляли в калибрах № 2, на них произведено 1406 т. Хотя объем металла, прокатанный в обоих калибрах, был примерно одинаковым, износ вторых калибров был существенно выше по сравнению с первыми. Так, максимальная выработка второго калибра 9-ой клети составила 0,34 мм, а первого только 0,2 мм. По-видимому, такое различие в характере их износа можно объяснить определенной наследственностью, связанной с прокаткой металла в предыдущих клетях. До поступления подката в первые калибры он прокатывался на относительно новых валках первых семи клетей, а ко вторым калибрам металл поступал после деформации в частично подношенных валках с несколько искаженной геометрией профиля. Следует также подчеркнуть, что различие в износе верхней и нижней половины калибра у валков 8-10 клетей практически незаметно, а микрорельеф их поверхности после кампании работы оставался гладким, без заметных изъянов и осповидности. Это следует из рассмотрения фотографий рис. 3.

На износ калибров валков определенное влияние оказывает также величина зазора между валками. При увеличении этого зазора вероятность сваливания раската в калибре возрастает, что отражается на его выработке.

\section{ВЫВОДЫ}

Разработана новая методика изучения износа валков проволочного блока, основанная на применении оптико-светового стенда и позволяющая оценить выработку ручья калибра по всему периметру сечения его. 
Проведен статистический анализ точности предложенного способа оценки износа в сравнении с показаниями часового индикатора. Проведенное исследование показало, что глубина износа калибров распределена неравномерно и существенно зависит от характера изменения среднего давления металла на валки по клетям проволочного блока.

При прокатке катанки диаметром 5,5 мм наиболее подвержены выработке калибры четвертой и пятой клетей, где преобладает абразивный износ. В первых двух клетях он приобретает вид осповидности.

\section{СПИСОК ИСПОЛЬЗОВАННОЙ ЛИТЕРАТУРЫ}

1. Крагельский И. В. Трение и износ / И. В. Крагельский. - 2-е изд., перераб. и доп. - М. : Машиностроение, $1968 .-480 c$.

2. Трение, изнашивание и смазка : справочник. В 2-х кн. / Под ред. И. В. Крагельского и В. В. Алисина. М. : Машиностроение, 1979. - 358 c.

3. Дроздов Ю. В. Противозадирная стойкость трущихся тел / Ю. Н. Дроздов, В. Г. Арчегов, В. И. Смирнов. - М. : Наука, 1981. - 139 c.

4. Тейбор Д. Износ. Краткий исторический обзор : пер. с англ. / Д. Тейбор // Проблемы трения и смазки. - М. : Мир, 1974. - № 4. - С. 6-16.

5. Хаккен Г. Синергетика : пер. с нем. / Г. Хаккен. - М. : Мир, 1980. - 440 с.

6. Воронцов Н. М. Эксплуатация валков обжимных и сортовых станов / Н. М. Воронцов, В. Т. Жадан, Б. Я. Шнееров и др. - М. : Металлургия, 1973. - 288 с.

7. Чекмарев А. П. Износ прокатных валков / А. П. Чекмарев, Р. А. Машковиев. - М. : Металлургиздат, 1955. - 147 с.

8. Быстров В.А. Условия эксплуатации и износ валков прокатного стана горячего металла / В. А. Быстров, П. К. Дьяков, А. Г. Уманеи // Известия вузов. Черная металлургия. - 2014. - № 5. - С. $24-29$.

9. Мур Д. Основы и применения трибоники : пер. с англ. / Д. Мур. - М. : Мир, 1978. - 487 с.

10. Румшиский Л. 3. Математическая обработка результатов эксперимента : справочное пособие / Л. 3 Румшиский. - М. : Наука, 1971. - 192 с.

11. Шенк Х. Теория инженерного эксперимента / Х. Шенк. - М. : Мир, 1972. - 381 с.

\section{REFERENCES}

1. Kragel'skij I. V. Trenie i iznos / I. V. Kragel'skij. - 2-e izd., pererab. i dop. - M. : Mashinostroenie, 1968. - 480 s.

2. Trenie, iznashivanie i smazka : spravochnik. V 2-h kn. / Pod red. I. V. Kragel'skogo i V. V. Alisina. - M. : Mashinostroenie, 1979. - $358 \mathrm{~s}$.

3. Drozdov Ju. V. Protivozadirnaja stojkost' trushhihsja tel / Ju. N. Drozdov, V. G. Archegov, V. I. Smirnov. M. : Nauka, 1981. - $139 \mathrm{~s}$.

4. Tejbor D. Iznos. Kratkij istoricheskij obzor : per. s angl. / D. Tejbor // Problemy trenija i smazki. - M. : Mir, 1974. - № 4. - S. 6-16.

5. Hakken G. Sinergetika : per. s nem. / G. Hakken. - M. : Mir, 1980. - 440 s.

6. Voroncov N. M. Jekspluatacija valkov obzhimnyh i sortovyh stanov / N. M. Voroncov, V. T. Zhadan, B. Ja. Shneerov i dr. - M. : Metallurgija, 1973. - 288 s.

7. Chekmarev A. P. Iznos prokatnyh valkov / A. P. Chekmarev, R. A. Mashkovcev. - M. : Metallurgizdat, 1955. - 147 s.

8. Bystrov V. A. Uslovija jekspluatacii i iznos valkov prokatnogo stana gorjachego metalla / V. A. Bystrov, P. K. D'jakov, A. G. Umanec // Izvestija vuzov. Chernaja metallurgija. - 2014. - № 5. - S. $24-29$.

9. Mur D. Osnovy i primenenija triboniki : per. s angl. / D. Mur. - M. : Mir, 1978. -487 s.

10. Rumshiskij L. Z. Matematicheskaja obrabotka rezul'tatov jeksperimenta : spravochnoe posobie / L. Z Rumshiskij. - M. : Nauka, 1971. - 192 s.

11. Shenk H. Teorija inzhenernogo jeksperimenta / H. Shenk. - M. : Mir, 1972. - 381 s.

Максименко О. П. - -д-р техн. наук, проф., зав. каф. ОМД ДГТУ;

Оробцев А. Ю. $\quad$ - канд. техн. наук, нач. техн. управл. ПАО «ДМК»;

Самохвал В. М. - канд. техн. наук, доцент ДГТУ;

Штода М. Н. — - канд. техн. наук, доцент ДГТУ;

Марченко К. К. - - аспирант ДГТУ.

ДГТУ - Днепровский государственный технический университет, г. Каменское.

ПАО «ДМК» - Публичное акционерное общество «Днепровский металлургический комбинат», г. Каменское.

E-mail: omd@dstu.dp.ua ; volsamokhval@gmail.com; maksshtoda@gmail.com 